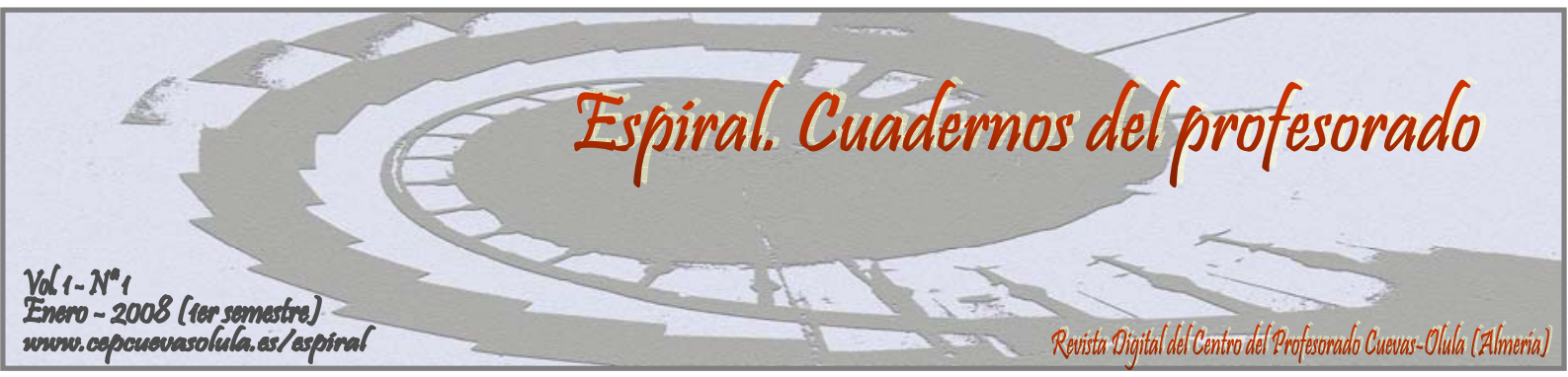

\title{
GÉNESIS Y DESARROLLO DE UNA BURGUESÍA LOCAL: EL CASO DE CUEVAS DEL ALMANZORA DURANTE EL SIGLO XIX.
}

\author{
Enrique Fernández Bolea \\ Profesor de Lengua Italiana en la E.O.I. de Macael (Almería) \\ Enviar correspondencia a: \\ enriquebolea@hotmail.com
}

\begin{abstract}
RESUMEN: Con el comienzo de la actividad minera en Sierra Almagrera a partir de 1839, el grupo de interesados en aquellas primeras sociedades explotadoras protagonizará uno de los enriquecimientos más espectaculares de la historia económica de España. Pero no fue sólo la fortuna lo que favoreció a aquellos privilegiados, ya que su anterior trayectoria de labradores y hacendados acomodados los había colocado en una posición idónea para aprovechar esa nueva y floreciente coyuntura económica que se inaugurará con la explotación de las minas del Jaroso. Los oligarcas agrícolas del XVIII mutarán, con el paso de los años y la incesante recogida de beneficios, en una nueva burguesía que irá adquiriendo plena conciencia de clase a medida que se esfuercen por alcanzar elementos de distinción comunes y se involucren en proyectos conjuntos beneficiosos para ellos y para la comunidad en la que se hallaban insertos.
\end{abstract}

Palabras clave: Cuevas del Almanzora, oligarquía, burguesía, sociedad, economía.

ABSTRACT: With the commencement of mining operations in Sierra Almagrera since 1839, the group of companies interested in those first operators will star in one of the most spectacular enrichment of the economic history of Spain. But it was not just the good fortune that favored those privileged, as his previous record of the affluent farmers and ranchers had placed uniquely placed to take advantage of this new and burgeoning economic climate that will open to the exploitation of the mines in Jaroso. The agricultural oligarchs in the XVIII century will change with the passage of years and the relentless collection of benefits, into a new bourgeoisie that will receive full class consciousness as they strive to achieve common elements of distinction and engage in joint projects beneficial to themselves and the community in which they were embedded.

Key words: Cuevas del Almanzora, oligarchy, bourgeoisie, society, economy.

1.- UNA EMERGENTE OLIGARQUÍA AGRÍCOLA: ANTECEDENTES Y EVOLUCIÓN.

A lo largo de este año 2007 se ha venido conmemorando el quinientos aniversario de la creación del Marquesado de los Vélez. Fue el 12 de octubre de 1507 cuando Juana la Loca, reina de España, otorga el título de marqués a Pedro Fajardo y Chacón. Este hecho, que podría ser considerado como uno de tantos acontecimientos que han jalonado nuestro devenir histórico, marcará sin embargo el destino de estos territorios hasta bien entrado el siglo XIX. Pero antes de esa concesión nobiliaria y tras un breve período de pertenencia al Corregimiento de Vera, las tierras de Cuevas y Portilla ya habían pasado por una jurisdicción señorial, primero bajo el efímero dominio -iniciado el 24 de junio de 1495- de Luis de Beaumont, condestable de 
Navarra $^{1}$, y más tarde -a partir del 23 de junio de 1503- bajo la autoridad del que sería futuro primer marqués de los Vélez que estableció en Las Cuevas una alcaldía mayor.

A partir de 1488, reconquistadas estas tierras del Bajo Almanzora a los árabes, se inicia un leve pero constante flujo migratorio desde los que, hasta ese momento, habían sido limítrofes reinos cristianos. Aproximadamente una década más tarde, un pequeño contingente de cristianos viejos -en torno a los cien- ya se habrá aposentado en Las Cuevas y Portilla ${ }^{2}$. Los recién arribados, hambrientos de tierras y asfixiados por una situación jurídico-social difícilmente soportable, hallarán en esta migración favorecida por la Corona la mejor oportunidad para enmendar unas circunstancias vitales sometidas al yugo de la servidumbre y el abuso de poder. El acicate no era otro que la adjudicación gratuita de tierras y, sobre todo, una importante exención tributaria.

Durante décadas, este reducido efectivo convivirá con una mayoría de musulmanes que desde entonces, con su forzada conversión al cristianismo, pasaron a denominarse moriscos. Pero la persecución y el intento de aniquilamiento de toda peculiaridad morisca culminó con el decreto de la Pragmática de 1566, cuya aplicación suponía la desaparición de cualquier manifestación, fuese de la índole que fuese, que permitiese distinguir o identificar su cultura, su lengua, sus hábitos o sus tradiciones. En esta cargada atmósfera de intransigencia religiosa e intolerancia cultural, en esta tendencia a eliminar cualquier rasgo de identidad, cualquier aspecto diferencial, se producirá la sublevación morisca de la Navidad de 1568, la cual se propagará, en forma de contienda, por toda la geografía del antiguo Reino de Granada hasta su conclusión en octubre de 1570.

Los moriscos que no se fueron con Aben Humeya tras el levantamiento de Las Cuevas y Portilla en septiembre de 1569 serán deportados, después de la guerra, a tierras de Castilla ${ }^{3}$, lo que

\footnotetext{
${ }^{1}$ Grima Cervantes, J. (1993). Almería y el reino de Granada en los inicios de la modernidad (s. XV-XVI) (pp. 161-162). Almería: Arráez Editores.

${ }^{2}$ Llaguno Rojas, P. (1989). La villa de las Cuevas durante el Antiguo Régimen (pp. 38-39). Cuevas del Almanzora-Almería: Ayuntamiento de Cuevas del Almanzora.

${ }^{3}$ Grima Cervantes, J. (1988). La expulsión morisca, el repartimiento y la repoblación cristiana de Turre
}

provocó - igual que ocurrió en todo el ámbito geográfico del Reino de Granada- un acusado despoblamiento de las tierras bajas del Almanzora y la imperiosa necesidad de promover una nueva repoblación con cristianos viejos. De este modo, el 7 de octubre de 1573 el Consejo de Población decidía la ubicación de 225 nuevos pobladores en Las Cuevas y 75 en Portilla. Pero los efectos de esta inyección de humanidad no duraron mucho, ya que la acción corsaria de El Dogalí, acaecida el 27 de noviembre de aquel mismo año, dio al traste con este intento repoblador: en el botín del pirata berberisco se incluían 243 personas entre hombres, mujeres y niños que serían vendidas en los mercados de esclavos del norte de África. A pesar del miedo que aquel avatar grabó en la memoria colectiva de la comarca, lo cierto es que la fama de feracidad que poseían las tierras cuevanas actuó como poderoso incentivo y, a los pocos meses (abril de 1574), ya se habían reunido 119 nuevos pobladores que, en 1577, habían aumentado hasta los 200 (unos 1.000 habitantes). Pero el éxito del proceso no se sustentaría exclusivamente en la buena calidad de la tierra, también habría sido favorecido por una relajación en las cargas tributarias ejercidas por la administración señorial sobre ese campesinado recién afincado, es decir a cambio del necesario aumento de población en un mundo hasta ese momento vacío $\mathrm{y}$, por tanto, improductivo, los marqueses se mostraron inicialmente dispuestos a sacrificar una parte de sus derechos señoriales que irían recuperando con la paulatina consolidación de esas comunidades campesinas en sus territorios ${ }^{4}$. Aquellos pobladores de 1574, en recompensa a la osadía de haberse trasladado a tierras tan peligrosas e inestables, recibieron lo que vinieron en denominarse suertes de población, es decir una casa donde cobijarse y un trozo de tierra con el que poder subsistir. Así, se compusieron 420 suertes que incluían cada una de ellas 12 fanegas de huerta, 38 y tres cuartos de tierra blanca de riego, nueve fanegas y media de secano, cinco celemines y medio de olivar, y dos celemines y tres cuartillos de moreras. Por aquellos años

(1570-1596). Colección documental para la historia de Turre (p. 48). Almería: Diputación Provincial de Almería y Ayuntamiento de Turre.

${ }^{4}$ Sánchez Picón, A. (2007). En torno al legado económico del régimen señorial velezano. Un apunte y algunas pistas (inédito). En Los señoríos en la Andalucía moderna. El Marquesado de los Vélez, 3-5 de mayo de 2007. 
finales del siglo XVI y durante el XVII la igualdad en la distribución de la propiedad no podía ser más rotunda, y sólo los distintos marqueses y algunos de sus súbditos -los que ocupaban los cargos señoriales de la villa- se destacaban sobre el común en una clara tendencia hacia la acumulación de haciendas y bienes.

Sin embargo, una oligarquía de hacendados comenzará a consolidarse a principios del siglo XVIII, momento en que, debido sobre todo a un aumento de la presión demográfica y a la promoción por parte del casa marquesal de algunas obras hidráulicas destinadas al aumento de los recursos hídricos, se producirá una ampliación notable de los regadíos de la vega cuevana $^{5} \mathrm{y}$ el consiguiente aumento de la riqueza rústica que comienza a concentrarse en manos de unos pocos privilegiados. Basta echar un somero vistazo al Catastro mandado elaborar por el Marqués de Ensenada ${ }^{6}$ para corroborar esa tendencia; y lo que es más interesante, para cerciorarse de cuáles fueron las familias que se involucraron en este proceso, porque esos apellidos volverán a tener presencia y protagonismo cuando se inicie la etapa de explotación minera casi un siglo después. Un caso a tener muy en cuenta, por lo que posee de clarificador y significativo, es el de los hermanos Soler Blázquez -Ginesa, Ana Ventura, Diego Nicolás, Alfonso y, sobre todo, el presbítero Francisco José-, entre los que se encuentra también Manuel José, padre de Miguel Soler Molina, quien con el transcurrir del tiempo se convertiría en el principal alentador del descubrimiento de metales en Sierra Almagrera y

\footnotetext{
${ }^{5}$ Sánchez Picón, A. \& Rodríguez Vaquero, J. (1989). Nuevos riegos en la Almería del siglo XIX. Ideas para un esquema (pp. 1.130-1.131). En El agua en zonas áridas: arqueología e historia. Actas del I Coloquio de historia y medio físico, vol. II. Almería: Instituto de Estudios Almerienses; Sánchez Picón, A. (1997). Los regadíos de la Andalucía árida (siglos XIX y XX). Expansión, bloqueo y transformación (p. 115). Áreas, 17; Fernández Bolea, E. (2006). Agua y vida en Cuevas del Almanzora. Una historia de luchas y anhelos. (Siglos XVI-XXI) (pp. 115-126). Cuevas del Almanzora: Arráez Editores; y con referencia al crecimiento demográfico y aumento de la superficie cultivable en toda la provincia, véase García Latorre, J. \& García Latorre, J. (2007). Almería: hecha a mano. Una historia ecológica (pp. 247-259). Almería: Cajamar.

${ }^{6}$ Catastro del Marqués de la Ensenada de la villa de Las Cuevas, Laicos, Archivo Municipal de Cuevas del Almanzora (AMCA en nuevas citas), libs. 1224 y 1226.
}

el fundador de la primera sociedad minera Carmen y Consortes. Pero ya por entonces, el mismo documento describe las profusas propiedades de los Bravo Gallardo, Márquez Albarracín, Márquez Peñuela, Abellán Segura, Flores Monge, Mula Martínez, Peñuela Mula y otras combinaciones patronímicas que tanto se prodigarán en la etapa inaugurada a partir de 1839 y que, junto al Marqués de Villafranca y los Vélez, reunían en ese patrimonio rústico declarado amplias superficies repartidas por la huerta de riego y los pagos de secano ${ }^{7}$. Pero no sólo la propiedad de la tierra caerá en manos de estas familias reseñadas, también ejercían el control sobre cualquier forma de producción agraria, así como sobre la comercialización de los productos y sus beneficios. De este modo, antes del inicio de la actividad minera Sebastián Soler y Consortes, Joaquín de Lisa y Consortes, Diego Abellán y Consortes, Francisco Flores y Antonio Núñez Ortega, entre otros, controlaban la pujante industria harinera de la localidad, pues en sus manos se encontraban la mayoría de los numerosos artilugios pertenecientes a esta agroindustria que funcionaban en Cuevas a finales del XVIII ${ }^{8}$. Ahora bien, el camino hacia el dominio de ese sector productivo no anduvo exento de obstáculos, ya que la construcción de estos molinos promovida por la elite agrícola de la localidad será entendida por la casa marquesal como un atentado contra sus pretensiones monopolistas. De esta situación de abierto enfrentamiento se derivaron dilatados y costosos pleitos que se sucedieron desde principios del siglo XVIII, en los que se intentó determinar, en ocasiones, si el otorgamiento de licencia para la construcción de aquellos artilugios correspondía al señor jurisdiccional o al juez de la Real Población ${ }^{9}$.

\footnotetext{
${ }^{7}$ Catastro del Marqués de la Ensenada de la villa de Las Cuevas, Laicos, AMCA, libs. 1.225 y 1.226; y Eclesiásticos, lib. 1.249.

${ }^{8}$ Fernández Bolea, E. (2006). Op. cit. (p. 100, cuadro 2).

${ }^{9}$ Los datos provienen de la consulta realizada por el profesor Sánchez Picón a la documentación del Archivo Ducal de Medina Sidonia (legs. 519 y 527), algunas de cuyas conclusiones se insertan en su artículo "En torno al legado económico del régimen señorial velezano. Un apunte y algunas pistas”, presentado en el congreso internacional Los señoríos en la Andalucía moderna. El Marquesado de los Vélez, 3-5 de mayo de 2007.
} 
Próximos ya al descubrimiento, fruto del preamillaramiento acometido por el concejo de Las Cuevas en 1818, se va a desvelar la continuidad de las mismas familias en esa tendencia a la acumulación y control de la riqueza rústica de la villa, hasta el punto de que el $11,8 \%$ de los propietarios poseerán el 74,2\% de toda la tierra susceptible de ser cultivada ${ }^{10}$. Pues bien, entre los contribuyentes que cuentan con un capital superior a 25.000 reales nos volvemos a encontrar al fundador Soler Molina, quien con 62.250 ocupa un puesto intermedio en esta particular clasificación en la que nuevamente figuran, de modo destacado, los Mula, Alarcón, Abellán, Casanova, Márquez y el resto de los apellidos que integrarán el núcleo más relevante de la futura burguesía cuevana.

Pues bien, esta tendencia a la concentración de tierras se hallaba imbricada en la mentalidad dominante del Antiguo Régimen -tanto tienes, tanto puedes- por la que se preconizaba la superioridad de unos sobre otros dependiendo de la importancia de la hacienda. Y es que la posesión e incremento de tierras suponía un seguro pasaporte hacia la obtención de la hidalguía o -lo que era considerado de mayor relevancia- hacia el acaparamiento de cargos en el cabildo. Con una ligera ojeada a las composiciones del concejo de la villa de Cuevas en los años inmediatamente anteriores a la señera fecha de 1839 -entre 1790 y 1821, ya que no se conservan las actas capitulares ${ }^{11}$ entre este último año y 1839-, comprobaremos que determinados apellidos se convierten en dominantes a la hora de acaparar los cargos de alcaldes mayores, alcaldes ordinarios, regidores y diputados municipales: nuestro Miguel Soler Molina aparece como regidor en 1799 y es propuesto para ocupar una de las alcaldías ordinarias en $1814^{12}$; de igual modo, sus hermanos Sebastián y Manuel ostentan el cargo de regidor en reiteradas ocasiones; y otro tanto ocurre, como no podía ser de otro modo, con los Albarracín, Mula, Peñuela, Abellán, Bravo, Márquez, Flores, etc.

Es decir, ya en los prolegómenos de aquella eclosión minera que protagonizarán Cuevas y su

\footnotetext{
${ }^{10}$ Sánchez Picón, A. (1992). La integración de la economía almeriense en el mercado mundial (17781936). Cambios económicos y negocios de exportación (p. 191). Almería: Instituto de Estudios Almerienses.

${ }^{11}$ Actas capitulares, 1790-1820, AMCA, libs. 70-85.

12 “Cabildo”, 11 de marzo de 1815, en Actas Capitulares, AMCA, lib. 83.
}

comarca, una minoría de familias se habrá consolidado como clase pujante al aglutinar bajo su propiedad buena parte de la superficie cultivable, fundamento económico casi exclusivo de una sociedad básicamente agrícola; y como consecuencia de este dominio sobre la única fuente de producción surgirá el exhaustivo control de los centros locales de poder representados por la alcaldía mayor y el concejo. $\mathrm{Y}$ por si esto fuera poco, el paulatino afianzamiento político y económico de este grupo de labriegos ricos y acomodados coincidirá, a partir de 1811, con sucesivas medidas legislativas que apuntarán hacia la abolición de los señoríos jurisdiccionales y de los privilegios que de ellos emanaban. Todo está preparado para afrontar con éxito la nueva etapa que les sorprenderá unos años después, puesto que serán los miembros de estas familias privilegiadas los mejor posicionados en esa carrera especulativa que se desbocará durante la década de 1840.

\section{2.- EN LOS PRELIMINARES DE UNA NUEVA CLASE: LA CONSOLIDACIÓN ECONÓMICA.}

El Real Decreto de 4 de julio de 1825 supuso un aliciente legislativo de primer orden para el fomento de la minería y la inclusión de este sector en los procesos económicos capitalistas ${ }^{13}$, porque no hay que olvidar que hasta ese momento la explotación de las minas repartidas por todo el ámbito geográfico nacional estaban bajo el rígido control de la Corona, permitiendo ésta en ocasiones la incursión de pequeñas compañías explotadoras obligadas a firmar contratas donde el Estado ejercía el más férreo de los monopolios sobre la comercialización y distribución de los minerales, pues toda la producción debía tener como único destino -lo demás se consideraba contrabando- los almacenes de la Real Hacienda, con la que previamente se había acordado un precio de compra por arroba de mineral extraído. Sin duda, aquella nueva coyuntura legislativa va a favorecer la penetración de la iniciativa privada en el sector, lo que, unido al conocimiento que se poseía sobre la existencia de antiguos criaderos de mineral en Almagrera y a la explotación de

\footnotetext{
${ }^{13}$ Sánchez Picón, A. (1983). La minería en el Levante almeriense 1838-1930. Especulación, industrialización y colonización económica. Almería: Cajal.
} 
algunos de ellos en época reciente ${ }^{14}$, actuó como revulsivo para que algunos personajes como Soler Molina o el enigmático Julián López Salcedo iniciaran reconocimientos y exploraciones en aquellos solitarios barrancos en busca de la legendaria plata de fenicios, cartaginenses y romanos. Sea como fuere, sus sospechas terminaron por confirmarse, y el 24 de junio de 1839, tras haber dado con el rico filón Jaroso, se demarcaban las minas Carmen, Ánimas y San Cayetano. Entre tanto, Soler Molina había promovido, no sin dificultades e incomprensiones, la creación de la sociedad Carmen y Consortes que, con sus treinta y una acciones, supondrá el pistoletazo de salida a un proceso galopante que casi agotará la superficie susceptible de ser demarcada: en 1840 más de 1.700 agujeros con nombres de mina colonizaban la mayoría de los barrancos y quebradas de Almagrera $^{15}$, y se encontraban unos tan cerca de los otros que, "cuando se trató después de darles las demarcaciones -según la legislación de 1825, no se pudo verificar en algunos casos reuniendo tres agujeros $" 16$.

El promotor Soler, procedente -como sabemos- de una rancia familia de hacendados, además de involucrar a sus hijos en lo que él suponía un prometedor negocio, se dirigirá a otros propietarios con liquidez suficiente para poder responder a las cantidades que se exigían por acción (1.000 reales) o parte de acción. Entre

${ }^{14}$ Desconocido hasta ahora -al menos se carecía de base documental para sustentarlo- fue el negocio minero iniciado por Miguel Soler Molina, su hermano Manuel, su cuñado Jacinto Flores y otros individuos, quienes firmarían el 14 de enero de 1811 y ante Dionisio Lozano Cordero, administrador de las Rentas Reales de Vera y su Partido, una contrata con la Real Hacienda, que por entonces ejercía el monopolio sobre cualquier explotación minera dentro del reino de España ${ }^{14}$, teniendo como base la denuncia de una mina situada en el Cerro Bajo, jurisdicción de la villa de las Cuevas. A partir del 9 de mayo de aquel mismo año iniciarán la extracción de alcohol o galena, actividad que se mantuvo por lo menos hasta 1815. "Cabildo”, de 11 de marzo de 1815, y “Testimonio”, de 15 de marzo de 1815, en Actas Capitulares, AMCA, lib. 83.

${ }^{15}$ Ezquerra del Bayo, J. (1841). Descripción de la Sierra Almagrera y de su riqueza actual (p. 248). Anales de Minas, II.

16 Madoz, P. (1845-1850). Diccionario geográficoestadístico-descriptivo de España y sus posesiones de ultramar. Madrid. Voz Almagrera, p. 29 (publicado en edición facsímil en Valladolid: Ámbito-Editoriales Andaluzas Unidas, 1988). éstos, como no podía ser de otro modo, nos encontramos apellidos que nos resultan tan familiares -aparte de los Soler- como los Mula, Márquez, Flores, Bravo, Albarracín, Segura o Abellán, por citar sólo los principales ${ }^{17}$. Algunos de estos inversores los volveremos a hallar en otras sociedades ricas como Esperanza -la de los curas- u Observación -la de Ramón Orozco-; sólo sería preciso un vistazo superficial a los listados de interesados en ambas sociedades para ratificar lo que decimos ${ }^{18}$. Nos hallamos en una primera etapa de las explotaciones mineras de Almagrera, que se extenderá hasta la segunda mitad de la década de 1860, en que el laboreo de las minas se encontraba en manos de pequeñas sociedades locales cuyos miembros, en algunos casos, se enriquecieron aceleradamente, tanto que el desembolso inicial en la compra de participaciones, con ser muy considerable, resultó al final insignificante ante el imparable aumento del valor de las acciones en el mercado bursátil de Madrid: esos mil reales de media que costaron las acciones de las llamadas minas ricas -Carmen, Observación y Esperanza- muy pronto se convertirán en un millón o incluso más, ya que el precio de Observación, por ejemplo, se llegó a aupar hasta la exorbitante cifra de 1.440.000 reales; cada acción de Carmen, por su parte, produjo entre 1840 y 1847 más de un 1.000 .000

${ }^{17}$ Los socios originarios de Carmen y Consortes fueron: Miguel Soler Molina, Diego Abellán Flores, Torcuato Soler Bolea, Miguel Soler Flores, Andrés Alarcón Barrera, Francisco Alarcón de la Barrera, Manuel Bernabé Granados, Manuel José Soler Flores, Pedro Lledó Valdivia, Francisco Lledó Valdivia, José Lledó Valdivia, Julián López Salcedo, Miguel Soler Bolea, Blas Gilbel, Luis Grisolía, Antonio Soler Márquez, Antonio Fernández Fernández, Alonso Mula Fernández, Martín Alarcón Flores, Gregorio Márquez Pérez, Ginés Ponce Gómez, Francisco Rojas, Andrés López (a) Perdigón, Pedro Bravo, José Manuel Rodríguez Campoy, Pedro Valero Llerena, Diego Segura Guevara, Juan Antonio Flores Masegosa, Josefa Albarracín Pérez, Juan de la Cruz Soler Flores, Anastasio Flores Márquez, José Gómez Márquez, Andrés Alarcón Gómez, Pedro José Soler Flores, Francisco Soler Flores, Francisco Pérez, Diego Mula Fernández, Josefa Mula Fernández, Francisco Gómez Gil, Pedro Flores Soler y Luis Ramírez Gallardo. Esta relación se incluye en Bernabé Lentisco, A. M. (1894). Recuerdos de antaño. La primera transferencia de acciones de mina. El Minero de Almagrera, 962, 1 de marzo de 1894.

${ }^{18}$ Sánchez Picón, A. (1992). Op. cit. (p. 190, Cuadro IV.19 Lista de los socios originarios de las minas ricas de Almagrera). 
de reales de beneficios ${ }^{19}$; y otro tanto les ocurriría a los socios de Esperanza, quienes en ese mismo período incrementaron llamativamente sus arcas con el reparto de más de 35 millones de reales ${ }^{20}$. Y durante unos treinta años los afortunados mineros de estas primeras prospecciones no dudarán en dirigir esos sustanciosos réditos hacia la compra de participaciones en otras sociedades que incesantemente se constituían y que, cuando no fracasaban, contribuían al incremento de su capital y patrimonio. Como tampoco titubearon a la hora dirigir una parte de sus inversiones hacia otras actividades incipientes como las primeras fábricas de fundición, para cuya puesta en marcha volvieron a constituirse en sociedades de accionistas $^{21}$.

Pero si hay una particularidad que va a unir a todos estos agraciados por la diosa Fortuna en los primeros tiempos de la actividad de Almagrera, ésta será indudablemente la prioritaria dirección que seguirán las cuantiosas ganancias obtenidas. $\mathrm{Y}$ es que aquellos socios, obnubilados por una riqueza que colmaba con creces las más optimistas

19 "Utilidades líquidas que ha percibido cada una de las 30 acciones de que consta la Sociedad Especial Minera carmen y Consorte”, en El Minero de Almagrera, 453, 1 de agosto de 1883, p. 1.

${ }^{20}$ Sánchez Picón, A. (2006): La empresa autóctona del plomo en la expansión minera española del siglo XIX (pp. 142-143). En M. A. Pérez de Perceval, M. A. López-Morell \& A. Sánchez Rodríguez (eds.), Minería y desarrollo económico en España. Madrid: Síntesis.

${ }^{21}$ Buen ejemplo es la creación, a instancia de Manuel Soler Flores, el 2 de enero de 1844 de la Sociedad $L a$ Carmelita que constaba de 16 acciones. Para que nos hagamos una idea del monopolio que ejercieron determinadas familias sobre los medios de producción de la localidad, merece la pena mencionar el listado de accionistas: Manuel Soler Flores, 1 y 3/4 acciones; Miguel Soler Molina, 1 y 1/2 acciones; Miguel Soler Flores, 1 acción; Torcuato Soler Bolea, 1 y 1/2 acciones; Miguel Soler Bolea, $1 / 2$ acción; Francisco Soler Flores, 1/2 acción; Juan de la Cruz Soler Flores, 1/2 acción; Joaquina Márquez Mula, 1/2 acción; Martín de Alarcón Flores, 1⁄2 acción; Diego Abellán Flores, 1 acción; Andrés Alarcón Gómez, 1 acción; Francisco Alarcón Barrera, 1 acción; Diego Segura Guevara, 1/2 acción; Juan Antonio Flores Masegosa, 1/4 de acción; Anastasio Flores Márquez, 1/4 de acción; Francisco Albarracín Bravo, 1/4 de acción; Pedro Valero Llerena, 3/4 de acción; Gregorio Márquez Pérez, 1/2 acción; Alonso Mula Fernández, 1/2 acción; Diego Mula Fernández, 1/2 acción; Josefa Mula Fernández, 1/2 acción; José Manuel Rodríguez Campoy, 1/2 acción; e Isabel Lentisco Martínez, 1/4 de acción. En El Minero de Almagrera, 266, 24 de agosto de 1879 . expectativas, prescindirán -pecando, eso sí, de imprevisores o, según otra opinión, de codiciosos- de destinar una parte de los beneficios a la mejora de las instalaciones mineras o a la modernización de sus primitivos sistemas de extracción; sólo a partir de 1847, cuando la inundación se haga patente en el subsuelo de Almagrera y obstaculice los procesos de extracción, repercutiendo así sobre la rentabilidad de las explotaciones, aquellos confiados partícipes no tendrán más remedio que afrontar el problema con cuantiosas inversiones. No obstante, el grueso de las mismas fue destinado históricamente a la adquisición de predios en los mejores pagos de huerta y río de la localidad, y cuando éstos se agotaron, trascendieron los límites del municipio para comprar en las jurisdicciones vecinas, en otras provincias limítrofes o, incluso, en algunas a considerable distancia de Cuevas. Uno de esos destinos foráneos hacia el que se trasladaron con una cierta preferencia los capitales de Almagrera fue la extensa y feraz vega de Lorca, donde algunos opulentos cuevanos llegaron a convertirse en grandes propietarios rústicos que finalmente decidieron afincarse en la ciudad murciana para administrar con mayor eficacia su considerable hacienda; fue le caso de Jaime Arcas Martínez, Dolores Soler Flores o Miguel Abellán Pinar, por citar los ejemplos más notables, cuyas familias se aposentaron muy solidamente en Lorca, invirtiendo cuantiosos capitales no sólo en tierras sino también en el otro elemento que otorgaba poder a quien lo poseía: las aguas del alporchón lorquino ${ }^{22}$. No menos significativas fueron las inversiones de José Sánchez Puerta, párroco de Cuevas y fundador de la sociedad Esperanza, quien llegó a realizar importantes adquisiciones de fincas rústicas en las vegas de Motril y Almería $^{23}$; o las de Atanasio Márquez, quien, además de ser uno de los mayores contribuyentes de Almería, poseía un enorme patrimonio rústico en las provincias de Valencia y Castellón.

Lo cierto es que esta tendencia a dirigir las copiosas ganancias hacia la prioritaria adquisición de propiedad rústica agrupará a estos privilegiados en diversas iniciativas encaminadas todas ellas al aumento del valor de las tierras recién adquiridas y las que ya formaban parte del patrimonio familiar. En efecto, a partir de marzo

${ }^{22}$ Gil Olcina, A. (1993). La propiedad de las aguas perennes en el sureste ibérico (pp. 249-250). Alicante: Universidad de Alicante (ed. electrónica).

${ }^{23}$ Sánchez Picón, A. (1992): Op. cit. 
de 1842 se retoma un viejo proyecto que, por falta de liquidez, siempre había fracasado o había quedado en el olvido: la extracción, mediante la construcción de una galería de captación, de las aguas subálveas del río Almanzora. Para tal fin se constituyó lo que dio en denominarse Empresa o Junta de Aguas que, coordinada y dirigida por el Ayuntamiento a través de su alcalde, Diego Abellán Flores -uno de esos privilegiados con participación accionarial en más de una sociedad rica-, aunaba los esfuerzos de todos los hacendados de la localidad en el objetivo común de garantizar en cualquier circunstancia la dotación de aguas para riego a las feraces tierras ribereñas del Almanzora ${ }^{24}$. Si nos detuviésemos un instante en el elenco de nombres que están promoviendo con mayor actividad esta empresa, nos percataríamos de que más de la mitad de los reseñados poseían intereses en una o varias de las sociedades ricas que por entonces operaban en Sierra Almagrera. Destacan, sin duda, los casos del mencionado alcalde Abellán Flores, con dos acciones en Carmen y media en Observación; o el de los clérigos Torcuato Soler Bolea, con dos en Carmen y una en Esperanza, y José Sánchez Puerta, que poseía una acción en Observación y otra en Esperanza; o Miguel Soler Molina y su hijo Manuel Soler Flores, cada uno de ellos con dos acciones en Carmen. En definitiva, nos encontramos ante un grupo de emergentes acaudalados que ven incrementar sus fortunas a medida que se aplican los sustanciosos repartos de beneficios, pero además se trata de miembros de familias con tradición de propietarios de tierras, cuya única y común ambición se sustenta en el aumento de la hacienda como signo de poder económico y social (1992).

\section{3.- HÁBITOS, USOS Y NEGOCIOS: LA CONCIENCIA DE CLASE.}

A estas lógicas pretensiones de consolidación y afianzamiento de su poderío económico se sumarán las no menos comunes de mostrar al resto de la población significativos elementos de distinción social. Entre 1842 y 1850 estos hacendados metidos a mineros protagonizarán una pequeña revolución urbanística que, si bien no obedeció en ningún momento a unos criterios previos de planificación, sí transformó sensiblemente el semblante urbano de la localidad. La antigua planta morisca, de calles estrechas, irregulares y serpenteantes, quedará irreconocible a medida

\footnotetext{
${ }^{24}$ Fernández Bolea, E. (2006). Op. cit. (pp. 126-147).
}

que se vayan levantando edificios de nueva planta, sobre todo en las inmediaciones de los dos centros de poder: la iglesia parroquial y el cabildo. Muchos de aquellos accionistas que, en algunos casos, ya han recibido millones de reales a cambio de los pocos miles que invirtieron inicialmente, dedican una parte de esa inmensa fortuna en comprar pequeñas casas colindantes, derruirlas y, en los grandes solares resultantes, construirse sobrios palacetes que pronto se erigen en símbolos de su pujante posición socioeconómica. Fachadas neoclásicas e historicistas con preciosista rejería en sus vanos contienen pequeñas joyas ornamentales como pinturas al temple en techos y paredes, mármoles en columnas, suelos y escaleras, y nobles trabajos de ebanistería en puertas, ventanas y algunos artesonados. No se repara en gastos, y los artesanos y artistas se desplazan desde otros puntos de la geografía nacional para atender esta demanda de ostentación.

Con el paso de los años, algunos de estos profesionales destacarán con luz propia en el panorama de la arquitectura y decoración locales. Un caso paradigmático, por haberse convertido en referente de otros que le sucedieron, fue el de José Capel Cano -el maestro Capel como era conocido entre sus coetáneos- quien, además de distinguirse como "un superior ebanista -su especialidad más cultivada-, era un dibujante sobresaliente, un tallista de primer orden y un especial adornista", despuntando de igual modo "como arquitecto [que] hizo planos de singular mérito y dirigió con rara pericia muchas edificaciones [...]”25. Llama la atención esa labor integral y multidisciplinar que desplegó durante su dilatada actividad, aceptando todo tipo de encargos por dificultosos que éstos resultasen, aunque los más descollantes sin duda fueron los dirigidos a ornamentación de interiores, tanto en edificios civiles como religiosos: "Imposible nos es reseñar [...] las innumerables obras que debidas a su prodigiosa inteligencia han hecho su nombre notable, pero no dejaremos de citar los magníficos retablos de los altares de la Virgen de Guadalupe y de San José, los dos púlpitos y la sillería del trascoro de esta parroquia -todo destruido durante la Guerra Civil-, y el lujoso y artístico mobiliario de la casa del difunto D. Torcuato Soler

${ }^{25}$ De esta manera se expresa El Minero de Almagrera al publicar su necrológica en el $n^{\circ} 917$, de 18 de marzo de 1893, p. 4, habiéndose producido su óbito el día anterior. 
Bolea”26. Su sapiencia en arquitectura condujo a algunos de los facultativos del momento a tener en mucha consideración sus recomendaciones técnicas, de ahí que, por ejemplo, el ingeniero Antonio de Falces se apoyase estrechamente en los conocimientos de Capel para superar algunas de las numerosas dificultades que ofreció la construcción de la hermosa capilla promovida en 1854 por la sociedad Carmen y Consortes.

A la sombra de Capel Cano, y bajo su respetado magisterio, se curtió otra figura que aportaría lo mejor de sí misma a la arquitectura burguesa del momento; me estoy refiriendo al granadino José Tamayo Mairena, a quien se le encomendará a partir de 1852 "la dirección y levantamiento de las más importantes edificaciones" 27 , fuesen las moradas particulares de la clase más acomodada como otras construcciones destinadas a servicios públicos o colectivos. En definitiva, los artífices de la mutación urbanística de la Cuevas decimonónica siempre fueron los mismos, porque eran ellos y no otros los que merecieron la confianza de esa nueva clase pujante que volvía a encontrar en la vivienda una característica más en esa confluencia de elementos definidores. En este contexto, otro de los miembros de ese reducido grupo de técnicos o profesionales que disfrutó desde siempre de la fidelidad de aquellos burgueses fue Antonio de Falces, al que Antonio Abellán Peñuela, primer marqués del Almanzora, le encargó el magnífico palacete que poseía en Cuevas ${ }^{28} \mathrm{y}$, con casi absoluta certeza, el que después se haría levantar, con mayor suntuosidad, en la pequeña localidad de Almanzora (término municipal de Cantoria). Moritz Willkomm, viajero británico que transcurrirá una buena temporada recorriendo nuestro país, cuando llegue a Cuevas en el verano de 1847 no podrá disimular su sorpresa al describir las bondades que ofrece la población, otorgando fehaciente testimonio del cambio acaecido durante los últimos años: "Aunque es una localidad pequeña, llama la atención por sus modernos edificios, muchos de ellos de noble estilo y dotados de elegantes balcones que dan prueba de la prosperidad de sus habitantes, pero aún más

\footnotetext{
${ }^{26}$ Ibídem.

27 “D. José Tamayo Mairena”, en El Minero de Almagrera; y Fernández Bolea, E., Viudez Asensio, F. \& Alarcón Soler, J. M. (2002). Guía turística, cultural y patrimonial de Cuevas del Almanzora. Manuel para propios y extraños (pp. 90-91). Cuevas del Almanzora: Asemcal.

${ }^{28}$ Actas Capitulares, 10 de marzo de 1870, leg. 104, AMCA.
}

impresionantes son sus bellos patios y jardines, que ofrecen los más exóticos frutos tropicales. El pueblo cuenta con buenas posadas y casa de pupilos, elegantes comercios, agradables cafés y otros lujos inesperados en medio de este desierto. No obstante, este esplendor es muy reciente"29.

$\mathrm{Y}$ mientras se construye y proliferan los servicios, los nuevos propietarios exigen la alineación de calles y la ampliación de las mismas para que sus nuevas moradas luzcan con el esplendor merecido, y requieren de la autoridad municipal es decir de ellos mismos- la construcción de pequeños espacios que, como los parterres ajardinados, contribuyan a su solaz y esparcimiento. El principal artífice de esta progresiva transformación urbana será el ingeniero Antonio de Falces Yesares, hombre polivalente como pocos que alternó a lo largo de su etapa profesional la dirección facultativa de numerosas explotaciones mineras de Almagrera y, durante más de veinte años, de "las obras subterráneas para el alumbramiento de las aguas del río Almanzora”, con numerosas intervenciones de tipo urbanístico y arquitectónico. Muy conocido y apreciado por la emergente burguesía cuevana, contó por aquellos años centrales del siglo XIX con la confianza de los representantes municipales, nombrándolo miembro de la Comisión de Ornato Público. A él y a José Capel Cano, antiguos colaboradores en otras construcciones señeras de la localidad como la capilla de la Virgen del Carmen, se les encargarán los planos para la rehabilitación y reforma del edificio consistorial y las dependencias anexas del pósito, los cuales, en las postrimerías de 1859, presentaban notables deficiencias y un estado general de conservación deplorable. A su dirección se debió la primera ordenación y ajardinamiento de la plaza de la Constitución, así como el levantamiento del parterre inmediato a la iglesia parroquial -llamado durante un tiempo Paseo de Alfonso XII- con la distribución de su arbolado. Entre 1872 y 1874, esta vez acompañado de José Tamayo Mairena en la función de encargado de obras, dirigirá los trabajos de acerado y arrecifado de las calles más céntricas de la loca$\operatorname{lidad}^{30}$. A finales de la década de 1870 el centro urbano de Cuevas en nada se parece a aquel caó-

\footnotetext{
${ }^{29}$ Willkomm, Moritz (1997). Dos años en España y Portugal. Granada: Fundación Caja Granada.

${ }^{30} \mathrm{Si}$ se quiere profundizar más en sus intervenciones urbanísticas, véase Fernández Bolea, E. (2004). El ingeniero Antonio de Falces y la capilla de la Virgen del Carmen (pp. 51-58). Cuevas del Almanzora: Arráez Editores.
} 
tico y abigarrado conjunto de casas bajas construidas con elementos de escasa nobleza; ahora la burguesía ha modificado su entorno y con él ha ido cambiando sus costumbres, cada vez más elitistas y refinadas.

En los inicios de aquel apogeo urbanístico hacia 1845- arribó a Cuevas, requerido por Torcuato Soler Bolea, Andrea Giuliani Cosci ${ }^{31}$, pintor de origen italiano afincado en Madrid desde muy joven. El rico presbítero le ha encargado varios lienzos, entre los que se encuentra un retrato de cuerpo entero de su propia persona que obedece a esa costumbre de nobles y burgueses de ofrecer su imagen a la posteridad a través de la pintura. Hay que decir que esta primera obra actuará como detonante para que otros destacados miembros, sobre todo del clan Soler, soliciten los servicios de Giuliani, quien llega a convertirse casi en un pintor de cámara de esta familia, realizando tanto retratos individuales como de grupo, de los que aún se conservan numerosos ejemplos. Esta costumbre o inclinación social, de profunda significación burguesa, tendrá continuidad a finales de la década de 1860 cuando el pintor, miniaturista y fotógrafo lorquino Juan José Resalt ${ }^{32}$ se afinque en Cuevas y plasme sobre lienzo los semblantes de numerosos personajes de la ya consolidada burguesía local cuevana. De Resalt dijo su paisano Francisco Cáceres Pla, hombre de cultura muy vinculado a Cuevas por estrechos lazos familiares, lo siguiente: "Los trabajos favoritos del maestro son los cuadros alegóricos y decorativos, y los retratos, y en esta clase de obras pocos pueden aventajarle, de los contemporáneos; mas no por esto ha dejado de cultivar todos los géneros con buen éxito, y en cuantos lienzos ha puesto sus pinceles, ha demostrado que su potencia creadora es fecunda

\footnotetext{
${ }^{31}$ Haro Rivas, María de (1999). Restauración del retrato de D. Torcuato Soler Bolea, obra de Andrea Giuliani, 1845 (pp. 125-130). Axarquía, 4. Sobre su etapa en la capital almeriense, véase Nicolás Martínez, M. M. (2003). La pintura almeriense del período Fin de siglo. Problemática y estado de la cuestión (pp. 306307). En C. Rozalén Fuentes \& R. M. Úbeda Vilches (edits.), La crisis de fin de siglo en la provincia de Almería: el desastre del 98. Almería: Instituto de Estudios Almerienses.

${ }^{32}$ Fernández Bolea, E. \& Grima Cervantes, J. (2000). Memoria visual del siglo XX (1901-2000). La tarjeta postal ilustrada en Cuevas del Almanzora (pp. 20-21). Cuevas del Almanzora: Arráez Editores.
}

y su genio más superior todavía”33. Domiciliado en Cuevas por los mismos años de Resalt, destacó también el artista Antonio Limones, "conocido en esta población por sus aventajados dotes demostrados en las varias obras de pintura que ha ejecutado" ${ }^{34}$, tanto en retrato como en pintura al fresco de techos y paredes, prestigio que le llevó a ser elegido para la decoración de algunas casas de notables cuevanos o las nuevas dependencias municipales de Vera en 1879. Cuando se perfeccione el invento de Niepce y Daguerre, esta burguesía, vanidosa y siempre ansiosa de inmortalidad, comenzará a frecuentar los estudios de los fotógrafos, primero fuera de la localidad y, luego, cuando aquéllos acerquen sus servicios, dentro de la misma: Adolfo, Juan José Resalt, José Rodrigo, Romero del Río o Federico de Blain ${ }^{35}$ reflejaron para siempre los rostros, las actividades y costumbres de esta burguesía que ya posee un pleno sentimiento de clase.

Pero las inclinaciones culturales de este opulento grupo de privilegiados se encauzarán también mediante otras iniciativas y manifestaciones que perseguían ante todo la distinción y el refinamiento como peculiaridades de identificación de clase. Van a ser ellos mismos los encargados de promover espacios adecuados para el desarrollo de una actividad cultural y de esparcimiento a los que sólo tendrán acceso los componentes de la exclusiva clase pudiente de la localidad, la cual, dicho sea de paso, practicaba la endogamia más radical en todas y cada una de sus relaciones sociales. Surgirán entonces -ya en la década de 1850- centros como el Casino Principal o, más tarde, el Círculo Literario y Artístico, sociedad de carácter recreativo y cultural nacida del Café-Teatro de Valparaíso, primer espacio escénico permanente de la localidad. Hasta allí acudirá la buena sociedad en las grandes y pequeñas ocasiones, y por sus salones pulularán poetas y oradores, músicos y actores, con la particularidad de que, en su mayoría, estos actuantes amateurs pertenecen a

\footnotetext{
33 Cáceres Pla, F. (1913-1914). Hijos de Lorca (pp 221- 222). Lorca.

34 “Miscelánea”, en El Minero de Almagrera, 242, 1

de marzo de 1879, p. 2.

${ }^{35}$ Grima Cervantes, J. (1999). Memoria fotográfica de Garrucha (1838-1936): “La historia quieta”, Garrucha, 1999; Fernández Bolea, E. \& Grima Cervantes, J. (2000): Op. cit.; sobre la figura de Rodrigo, véase también Muñoz Clares, M. (2002). José Rodrigo 1837-1916. Murcia: Región de Murcia y Caja de Ahorros del Mediterráneo.
} 
las mismas familias que hasta allí se acercan en busca de entretenimiento. Con el paso del tiempo aquellas dependencias se convertirán en testigos mudos de saraos y reuniones sociales, discursos y homenajes, celebraciones de toda índole y significadas recepciones, representaciones teatrales y recitales poéticos, conciertos y hasta bailes de disfraces en tiempos de Carnaval. Niñas ricas que realizan sus primeros pinitos en el bel canto, vástagos virtuosos del violín y el piano, decentes señoras que interpretan el Tenorio, abogados que embelesan con su locuacidad, sabios clérigos que acercan la palabra sagrada, todos ellos ante un público presto a reconocer méritos y alardes, aunque los primeros y los segundos a veces brillen por su ausencia. Y entre tanto aficionado, de vez en cuando surge la figura de prestigio, el vate creador de poesía original, el fértil dramaturgo o el compositor inspirado que se convierten en baluartes de aquella peculiar cultura burguesa cuevana: Miguel Molina Valero $^{36}$, Felipe Pla y Meliá $^{37}$ o Antonio $\mathrm{M}^{\mathrm{a}}$ Bernabé Lentisco ${ }^{38}$, por citar a los más destacados. De este último merece apreciarse su incansable labor en pos de la música y su divulgación, con la creación de la primera banda de música de la localidad costeada de su propio peculio, la organización y dirección de una orquesta que envolvió con música los grandes acontecimientos de finales del XIX, o su aportación original a esta manifestación artística a través de la composición de zarzuelas, valses, porcas y algunas piezas religiosas.

Unas décadas después, esta misma elite, precisada de un espacio escénico más acorde con sus altas pretensiones, promoverá a través de una sociedad por acciones titulada La Recreativa la construcción de un casino-teatro que, en el

36 Fernández Bolea, E. (1999). Colaboraciones literarias de Miguel Molina Valero en El Minero de Almagrera (pp. 206-213). Axarquía, 4; véase también Martínez Navarro, P. E. (2007). Semblanzas, perfiles y notas biográficas de cuevanos y cuevanas ilustres (pp. 101-106). Cuevas del Almanzora: Ayuntamiento de Cuevas del Almanzora, y Fernández Bolea, E. (2006). Molina Valero, Miguel (p. 259), en J. P. Díaz López (coor.), Diccionario biográfico de Almería. Almería: Instituto de Estudios Almerienses y Cajamar.

37 "Miscelánea", en El Minero de Almagrera, no 716, 21 de enero de 1889, p. 3.

${ }^{38}$ Martínez Navarro, P. E. (2007). Op. cit. (pp. 85-91; y Fernández Bolea, E. (2006). Bernabé Lentisco, Antonio $\mathrm{M}^{\mathrm{a}}$ (pp. 64-65), en J. P. Díaz López (coor.), Op. cit. momento de su inauguración en 1888, rivalizará por su boato y dotación con algunos centros de esta misma clase ubicados en capitales de provincia. A partir de ese preciso momento obras de teatro, zarzuelas, actos públicos y reuniones mineras se sucedieron en aquella instalación, que se convirtió en templo de cultura, ocio y hasta negocio de la pujante burguesía que lo había impulsado ${ }^{39}$.

La prensa escrita, tan vinculada a la clase burguesa durante el XIX, va a contar en Cuevas con un señero exponente a partir de febrero de 1874, cuando ve por primera vez la luz El Minero de Almagrera. Su fundador y director, el rico minero Antonio $\mathrm{M}^{\mathrm{a}}$ Bernabé Lentisco, lo ideó como un órgano en defensa de los intereses generales de los mineros de los distritos de Almagrera y Herrerías y, más adelante, como el medio escrito oficial de los afectados por la empresa del Desagüe de Almagrera; sin embargo aquellas páginas recogieron a lo largo de sus 35 años de existencia -hasta su cierre en 1909- el devenir de toda una comunidad, aunque se prestase especial atención a los devaneos de la clase más favorecida, confeccionándose de este modo una dilatada y miscelánea crónica de sociedad en la que tuvieron entrada saraos, inauguraciones, visitas de ilustres, óbitos, nacimientos, homenajes y toda ese conglomerado de actos al que acudía con sus mejores galas nuestra atildada clase pudiente. Es verdad que, de modo incansable, la dirección de este periódico fue ejercida por Bernabé Lentisco hasta su muerte en 1901, momento en el que tomó el testigo su hijo Gregorio José; sólo durante un breve período -diciembre de 1878- que coincidió con la muerte de su esposa, $\mathrm{M}^{\mathrm{a}}$ de la Cueva Santa Soler Albarracín, delegó sus funciones en Salvador Rancel y Pintado, uno de los redactores y colaboradores más inquietos de El Minero ${ }^{40}$. En su larga trayectoria esta publicación convivió con otros periódicos de efímera existencia que quisieron competir, sin éxito, por el control de esa influencia mediática que ejercía el decano de la prensa cuevana. Muchos de los directores de esos nuevos órganos de opinión se habían curtido como redactores en las páginas de El Minero; así ocurrió con el mismo Rancel y Pintado, quien

\footnotetext{
${ }^{39}$ Fernández Bolea, E. \& Flores García, A. (2007). El teatro Echegaray de Cuevas del Almanzora, templo burgués de ocio y cultura (pp. 125-136). Axarquía, 12. 40 "Miscelánea", en El Minero de Almagrera, 232, 8 de diciembre de 1878, p. 4.
} 
sería responsable de un buen número de cabeceras como El Faro, La Razón Pública o La Conciencia Pública en su segunda época; o con el aventajado Martín Navarro Flores, profesor de la Institución Libre de Enseñanza, bajo cuya tutela salieron a la luz El Desagüe y El Cuevano $^{41}$. Hubo momentos del último cuarto del XIX en donde llegaron a coexistir hasta tres publicaciones periódicas, entablándose entre ellas interesantes debates como el que tuvo lugar durante el mes de enero de 1891 entre $L a$ Voz del Pueblo, El Combate y El Minero de Almagrera sobre la forma y el fondo de los artículos publicados por el segundo en referencia a las manifestaciones multitudinarias de diciembre de $1891^{42}$. El Imparcial Cuevano y la segunda época de El Eco del Almanzora cerrarán la prolífica presencia de medios escritos en Cuevas durante el último cuarto del siglo XIX. Hemos contemplado, pues, el mayor auge de la prensa escrita en esta localidad y en toda la provincia, asistiendo a la incesante publicación de cabeceras cuyos directores y redactores proceden de una única extracción social.

Y mientras tanto, los cachorros de la opulencia siguen los rígidos consejos de sus progenitores y protagonizan verdaderos contratos matrimoniales en los que ambas partes aportan, de mutuo acuerdo, fortunas similares. La oferta no era muy amplia y a veces se restringía tanto que los contrayentes solían pertenecer a una misma familia. Quizás el caso más drástico de endogamia en el seno de esta política matrimonial la protagonizaron los Soler, en

\footnotetext{
${ }^{41}$ El listado completo de los periódicos que convivieron con El Minero de Almagrera entre 1874 y 1895 es el siguiente: El Dómine Rancio, dirigido por Eugenio Cabeza Villanueva; Borracheras del Tío Cotho, por Luis Dinelli; El Eco del Almanzora, por Miguel González Henríquez; La Unión, por Julio Tena Campoy; El Faro, por Salvador Rancel y Pintado; La Conciencia Pública, por Andrés Márquez Navarro; El Combate, por Diego Navarro Gómez; La Voz del Pueblo, por José Flores Tovar; La Razón Pública, por Salvador Rancel y Pintado; El Defensor de los Mineros, por Andrés Federico de la Rosa; El Desagüe, por Martín Navarro Flores; La Conciencia Pública ( $2^{\mathrm{a}}$ época), por Andrés Márquez Navarro, primero, y Salvador Rancel y Pintado, después; El Anunciador, por Pedro Puerta; El Cuevano, por Martín Navarro Flores; y El Boletín de Cuevas, por Juan Antonio Núñez. En "La prensa de Cuevas", publicado en El Minero de Almagrera, ${ }^{\circ}$ 1.042, 25 de octubre de 1895, p. 1.

42 "Carta al director", en El Minero de Almagrera, 813, 29 de enero de 1891, pp. 2-4.
}

donde primos-segundos y hasta primos-hermanos materializaron sonadas uniones de las que resultaron fortunas muy considerables ${ }^{43}$. Fuera de los límites locales, los jóvenes cuevanos emparentaban con los hijos de aquellas otras familias de la comarca a las que el destino les había deparado igual suerte y fortuna. No obstante, los periplos de estas familias por Madrid, Barcelona, Valencia y otras grandes capitales de la época por motivos políticos, económicos u otros de carácter más frívolo posibilitaron estrechas relaciones con miembros de los clanes influyentes y adinerados, y en algunos casos esa amistad o simple relación mercantil se vio culminada por un matrimonio de conveniencia que, aparte de los capitales aportados por los contrayentes, concedía prestigio social a las familias involucradas ${ }^{44}$.

Entre los miembros de esta buena sociedad se propagaría un espíritu de conjunción de intereses comunes, de búsqueda de soluciones, que desembocó en iniciativas de tipo colectivo. Es cierto que, de 1875 en adelante y coincidiendo con los vientos de crisis que comenzaban a soplar desde los distritos mineros y la brutal sequía que se cernía sobre el campo cuevano, algunos descendientes de aquellos primeros accionistas, que ya cuentan con formación universitaria y desempeñan profesiones liberales, van a tomar las riendas de un movimiento asociativo que los aglutina como grupo con conciencia de clase ${ }^{45}$. El 3 de junio 1878 el gobernador civil aprobaba la constitución de la Sociedad Económica de Amigos del País ${ }^{46}$, entidad que recogía en sus objetivos la urgente necesidad de aprovechar la

${ }^{43}$ Ejemplo de lo que decimos fue el matrimonio habido entre Agustín Soler Ayas y Magdalena Soler Márquez que tuvieron un solo hijo llamado Francisco Soler Soler, uno de los mayores contribuyentes de la provincia a principios del siglo XX.

${ }^{44}$ Sería suficiente recordar la unión del diputado a Cortes Antonio Bernabé Soler, hijo de Antonio $\mathrm{M}^{\mathrm{a}}$ Bernabé y Lentisco, con la madrileña Carolina Montejo, hija del abogado y político progresista Telesforo Montejo y Robledo, quien participó en todas las acciones revolucionarios del liberalismo, siendo diputado a Cortes en 1869 y ministro de Fomento en 1871; o la de Félix Fernández Sánchez, hijo del opulento propietario y minero Diego Fernández Manchón, con Dolores Portal, también de acomodada familia madrileña. ${ }^{45}$ Fernández Bolea, E.\& Grima Cervantes, J. (2006). El fósil de Cirera y el Círculo Geológico Cuevense (pp. 16-27). Axarquía, 11.

46 "La Económica de Cuevas", en El Minero de Almagrera, $\mathrm{n}^{\circ} 208,12$ de junio de 1878, p. 3. 
unidad de acción como medio de progreso y desarrollo. Pero el desarrollo que alentaba no se reducía al incremento de la riqueza material, también y en igual proporción al progreso moral de la población, de ahí que, de modo paralelo a un necesario crecimiento económico y complementario de éste, fuese preciso incentivar las artes, las ciencias y las letras, ya que en su práctica, cultivo y difusión se hallaba uno de los pilares del futuro de los pueblos. Eran días de frenética actividad, pues el 3 de abril de 1878 el Gobierno había aprobado mediante Real Orden "las ordenanzas para el régimen y gobierno de las aguas de esta ciudad y los reglamentos orgánicos del Sindicato y Jurado" ${ }^{47}$, órganos igualmente primordiales para los intereses de los propietarios de tierras, cuyos directivos preconizarán desde el principio la ineludible necesidad de ir de la mano de la Económica en aquellas reivindicaciones que supusiesen prosperidad y adelanto para la localidad ${ }^{48}$. Lo cierto es que las directivas de una y otro coincidían bastante en su composición, tanto es así que la cabeza del organismo agrícola oteaba igualmente desde la cúspide de la Sociedad: el abogado José Piqueras Giménez, presidente de varias sociedades mineras, alcalde de Cuevas en los años siguientes, propietario de tierras y profesional de prestigio era un elevado referente para el grupo social cuyos intereses representaba; junto a él, destacaban otros miembros de ese mismo grupo que solían reiterar esfuerzos e inquietudes.

En definitiva, el ritmo siempre lo marcarán los mismos protagonistas, convirtiéndose esto en una constante de todas y cada una de las iniciativas posteriores, fuesen de la índole que fuesen. Por eso, no es de extrañar que, cuando se creen otro tipo de sociedades de carácter científico o cultural como el Círculo Geológico Cuevense, la ilustrada burguesía cuevana volverá a unirse en favor de la defensa, estudio y divulgación de un patrimonio histórico y natural que ellos consideraban de primer orden. De nuevo los apellidos Soler, Mula, Casanova, Márquez, Flores, Alarcón, Bernabé, etc. se arremolinan en torno a una empresa común ${ }^{49}$, haciendo gala de una sensibilidad ligada a una

\footnotetext{
47 “Junta general de regantes", en El Minero de Almagrera, $\mathrm{n}^{\circ} 204,10$ de mayo de 1878, pp. 1-3.

${ }^{48}$ Fernández Bolea, E. (2006). Op. cit. (pp. 148-168).

${ }^{49}$ La lista completa de los integrantes de esta Sociedad se incluye en Fernández Bolea, E. \& Grima Cervantes, J. (2006). Op. cit. (p. 22, nota 14).
}

clase que ya posee una formación cultural, porque entre ellos hay abogados, médicos, farmacéuticos, ingenieros o profesores tanto foráneos como hijos de aquellos primeros accionistas que consideraron acertado derivar un porcentaje de los beneficios hacia su educación y formación.

Pero ese mismo impulso colectivo del que tan a menudo hicieron alarde, volverá a ponerse de manifiesto cuando reivindiquen la creación de una institución educativa que, además de evitar el desplazamiento de sus cachorros hacia otras poblaciones durante el período de formación inicial y media, otorgue a la ciudad y a su clase dominante otro rasgo más de distinción acorde con su importancia económica. De esta forma, el 12 de junio de aquel prolífico 1878, como consecuencia de esa conjunción de esfuerzos destinados al progreso económico y moral de la localidad, el Ayuntamiento y los mayores contribuyentes acordarán la definitiva fundación de un colegio de primera y segunda enseñanza; para ello el Obispado de Almería cederá a perpetuidad y sin coste alguno el edificio que fue convento de la orden seráfica de San Francisco ${ }^{50}$. Desde el curso inaugural 1881-1882, por aquellas dependencias escolares pasaron y se formaron varias generaciones de estudiantes, en su mayoría vástagos de esa clase adinerada que había sido su promotora. A partir de 1892, el desprendimiento de María de la O Flores, rica integrante de la burguesía local, permitirá la reparación, mejora y ampliación del edificio, inaugurándose una nueva y floreciente etapa en la que la orden de los Dominicos regentará el establecimiento hasta $1919^{51}$.

Era indudablemente esa conciencia de clase que compartía necesidades, gustos, hábitos, relaciones y negocios, esa misma que se manifestaba cada vez que resultaba precisa una sola voz que clamase reformas y mejoras. Ellos seguían ocupando los cargos municipales y, como mayores contribuyentes, ejercían su poder e influencia sobre el funcionamiento de la institución y su política de gestión. Les preocupaba sobremanera el ornato público, la mejora de las infraestructuras urbanas, la creación de espacios para el esparcimiento y la

\footnotetext{
50 "Gran acuerdo", en El Minero de Almagrera, $\mathrm{n}^{\circ}$ 209, 22 de junio de 1878, pp. 1-2.

${ }^{51}$ Flores González-Grano de Oro, M. (1932). Las instituciones escolares en Cuevas del Almanzora (Almería). Cuevas del Almanzora: Imprenta de Campoy.
} 
dotación de servicios básicos que incidiera sobre su calidad y nivel de vida, y, por extensión, sobre la calidad y nivel de vida de toda la comunidad. Iniciativas tan trascendentales como la traída y dotación de aguas potables a la localidad tuvieron en la movilización de este sector burgués la clave de su relativo éxito, puesto que, si bien el Ayuntamiento otorgaba su respaldo al proyecto, eran los capitales de las enriquecidas familias los que lo ponían en marcha y lograban su conclusión ${ }^{52}$.

Ahora bien, nuestros burgueses, imbuidos de ese empuje transformador que comenzaba a cambiar el semblante de las grandes ciudades españolas, proponen una concienzuda planificación urbanística para Cuevas, y sus reivindicaciones se van a fundamentar en el incremento demográfico de la localidad gracias a la explotación e industria mineras y en la modernización de la misma para adaptarla a las exigencias de las nuevas sociedades. Reformas en los viejos cascos antiguos o espectaculares ensanches se están realizando en Barcelona, Bilbao o Madrid, con propuestas y supervisiones de eminentes urbanistas como Carlos $\mathrm{M}^{\mathrm{a}}$ de Castro o Ildefonso Cerdá. Aquí, con el Proyecto de Ensanche y Reforma de la Ciudad de Cuevas de 1880, que sigue principalmente las pautas de aquellos dos ingenieros, se pretende ganar en espacios comunes y ordenar el crecimiento urbano de un modo racional ${ }^{53}$. De aquel proyecto poco, por no decir nada, se materializó finalmente, aunque se han conservado los cinco volúmenes ${ }^{54}$ de estudios y planos que se erigen en testimonio de un espíritu de transformación y cambio auspiciado por aquel inquieto $\mathrm{y}$ emprendedor sector burgués que, al menos en el último cuarto del XIX, demostraron su confianza en la fuerza de clase y su poder de futuro y progreso.

\footnotetext{
${ }^{52}$ Fernández Bolea, E. (2001). La traída de las aguas potables a Cuevas del Almanzora. La trascendencia de una obra (pp. 73-83). Axarquía, 6; y Fernández Bolea, E. (2006). Op. cit. (pp. 240-280).

${ }^{53}$ Fernández Bolea, E. (2000). Una planificación urbanística irrealizada: Proyecto de ensanche y reforma de la ciudad de Cuevas (1880) (pp. 72-80). Axarquía, 5.

${ }^{54}$ Proyecto de ensanche y reforma de la ciudad de Cuevas, 1880, AMCA, leg. 651.
}

\section{4.- REFERENCIAS BIBLIOGRÁFICAS.}

Bernabé Lentisco, A. M. (1894). Recuerdos de antaño. La primera transferencia de acciones de mina. El Minero de Almagrera, 962, 1 de marzo, p. 4.

Cáceres Pla, F. (1913-1914). Hijos de Lorca. Lorca.

Ezquerra del Bayo, J. (1841). Descripción de la Sierra Almagrera y de su riqueza actual (p. 248). Anales de Minas, II, 237-253.

Fernández Bolea, E. (1999). Colaboraciones literarias de Miguel Molina Valero en El Minero de Almagrera. Axarquía, 4, 206-213.

Fernández Bolea, E. \& Grima Cervantes, J. (2000). Memoria visual del siglo XX (19012000). La tarjeta postal ilustrada en Cuevas del Almanzora. Cuevas del Almanzora: Arráez Editores.

Fernández Bolea, E. (2000). Una planificación urbanística irrealizada: Proyecto de ensanche y reforma de la ciudad de Cuevas (1880). Axarquía, 5, 72-80.

Fernández Bolea, E. (2001). La traída de las aguas potables a Cuevas del Almanzora. La trascendencia de una obra. Axarquía, 6, pp. 73-83.

Fernández Bolea, E., Viudez Asensio, F. \& Alarcón Soler, J. M. (2002). Guía turística, cultural y patrimonial de Cuevas del Almanzora. Manuel para propios y extraños. Cuevas del Almanzora: Asemcal.

Fernández Bolea, E. (2004). El ingeniero Antonio de Falces y la capilla de la Virgen del Carmen. Cuevas del Almanzora: Arráez Editores.

Fernández Bolea, E. (2006). Agua y vida en Cuevas del Almanzora. Una historia de luchas y anhelos. (Siglos XVI-XXI). Cuevas del Almanzora: Arráez Editores.

Fernández Bolea, E. (2006). Bernabé Lentisco, Antonio Ma ${ }^{\mathrm{a}}$. En J. P. Díaz López (Coord.), Diccionario biográfico de Almería (pp. 6465). Almería: Instituto de Estudios Almerienses y Cajamar.

Fernández Bolea, E. (2006). Molina Valero, Miguel. En J. P. Díaz López (Coord.), Diccionario biográfico de Almería (p. 259). Almería: Instituto de Estudios Almerienses y Cajamar. 
Fernández Bolea, E. \& Grima Cervantes, J. (2006). El fósil de Cirera y el Círculo Geológico Cuevense. Axarquía, 11, 16-27.

Fernández Bolea, E. \& Flores García, A. (2007). El teatro Echegaray de Cuevas del Almanzora, templo burgués de ocio y cultura. Axarquía, 12, 125-136.

Flores González-Grano de Oro, M. (1932). Las instituciones escolares en Cuevas del Almanzora (Almería). Cuevas del Almanzora: Imprenta de Campoy.

García Latorre, J. \& García Latorre, J. (2007). Almería: hecha a mano. Una historia ecológica. Almería: Cajamar.

Gil Olcina, A. (1993). La propiedad de las aguas perennes en el sureste ibérico. Alicante: Universidad de Alicante (Ed. electrónica).

Grima Cervantes, J. (1988). La expulsión morisca, el repartimiento y la repoblación cristiana de Turre (1570-1596). Colección documental para la historia de Turre. Almería: Diputación Provincial de Almería y Ayuntamiento de Turre.

Grima Cervantes, J. (1993). Almería y el reino de Granada en los inicios de la modernidad (s. $X V-X V I)$. Almería: Arráez Editores.

Grima Cervantes, J. (1999). Memoria fotográfica de Garrucha (1838-1936): "La historia quieta”, Garrucha.

Haro Rivas, María de (1999). Restauración del retrato de D. Torcuato Soler Bolea, obra de Andrea Giuliani, 1845. Axarquía, 4, 125130.

Llaguno Rojas, P. (1989). La villa de las Cuevas durante el Antiguo Régimen. Cuevas del Almanzora-Almería: Ayuntamiento de Cuevas del Almanzora.

Madoz, P. (1845-1850). Diccionario geográficoestadístico-descriptivo de España y sus posesiones de ultramar. Madrid. (Publicado en edición facsímil en Valladolid: ÁmbitoEditoriales Andaluzas Unidas, 1988).

Martínez Navarro, P. E. (2007). Semblanzas, perfiles y notas biográficas de cuevanos y cuevanas ilustres. Cuevas del Almanzora: Ayuntamiento de Cuevas del Almanzora

Muñoz Clares, M. (2002). José Rodrigo 18371916. Murcia: Región de Murcia y Caja de Ahorros del Mediterráneo.
Nicolás Martínez, M. M. (2003). La pintura almeriense del período Fin de siglo. Problemática y estado de la cuestión. En C. Rozalén Fuentes \& R. M. Úbeda Vilches (Ed.), La crisis de fin de siglo en la provincia de Almería: el desastre del 98 (pp. 301-310). Almería: Instituto de Estudios Almerienses.

Sánchez Picón, A. (1983). La minería en el Levante almeriense 1838-1930. Especulación, industrialización y colonización económica. Almería: Cajal.

Sánchez Picón, A. \& Rodríguez Vaquero, J. (1989). Nuevos riegos en la Almería del siglo XIX. Ideas para un esquema. En, El agua en zonas áridas: arqueología e historia. Actas del I Coloquio de historia y medio físico (Vol. II, pp. 1127-1149). Almería: Instituto de Estudios Almerienses.

Sánchez Picón, A. (1992). La integración de la economía almeriense en el mercado mundial (1778-1936). Cambios económicos y negocios de exportación. Almería: Instituto de Estudios Almerienses.

Sánchez Picón, A. (1997). Los regadíos de la Andalucía árida (siglos XIX y XX). Expansión, bloqueo y transformación. Áreas, 17, 109-128.

Sánchez Picón, A. (2006): La empresa autóctona del plomo en la expansión minera española del siglo XIX. En M. A. Pérez de Perceval, M. A. López-Morell \& A. Sánchez Rodríguez (eds.), Minería y desarrollo económico en España (pp. 127-151). Madrid: Síntesis.

Sánchez Picón, A. (2007). En torno al legado económico del régimen señorial velezano. Un apunte y algunas pistas (inédito). En Los señoríos en la Andalucía moderna. El Marquesado de los Vélez, 3-5 de mayo de 2007.

Willkomm, Moritz (1997). Dos años en España y Portugal. Granada: Fundación Caja Granada.

Publicaciones periódicas:

- El Minero de Almagrera

Fuentes archivísticas:

- Archivo Municipal de Cuevas del Almanzora

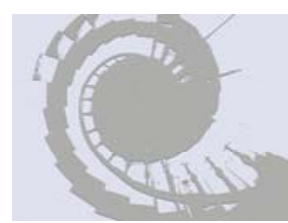

